\title{
REFLEXÃO SOBRE OS JOGOS DO PROJETO TEC IARA PARA A CONSERVAÇÃO DA ÁGUA E VALORIZAÇÃO DA CULTURA INDÍGENA
}

\section{ARTIGO ORIGINAL}

SANTOS, Janderson Igo Ferreira Guirra dos ${ }^{1}$, FERREIRA, Marcio Harrison dos Santos ${ }^{2}$, CARVALHO, Aurélio José Antunes de ${ }^{3}$

SANTOS, Janderson Igo Ferreira Guirra dos. FERREIRA, Marcio Harrison dos Santos. CARVALHO, Aurélio José Antunes de. Reflexão sobre os jogos do projeto TEC IARA para a conservação da água e valorização da cultura indígena. Revista Científica Multidisciplinar Núcleo do Conhecimento. Ano. 06, Ed. 12, Vol. 05, pp. 0531. Dezembro de 2021. ISSN: 2448-0959, Link de acesso: https://www.nucleodoconhecimento.com.br/educacao/conservacao-da-agua

\section{RESUMO}

O estudo que apresentamos trata-se de uma reflexão sobre ao uso do aplicativo TECIARA Jogos para aprendizagem e valorização da água nos territórios indígenas da Bahia, produzido pelo IF Baiano e financiado pela CAPES/ANA. O objetivo estabelecido para esta pesquisa foi descrever a percepção de professores, alunos e lideranças da comunidade indígena Kiriri em relação ao uso do aplicativo TEC-IARA. A metodologia utilizada foi à pesquisa de campo com caráter etnográfico, com o uso dos seguintes instrumentos de coleta de dados: diário de bordo, entrevista semiestruturada e registro fotográfico. Os resultados aqui apresentados proporcionaram como o programa TEC-IARA se torna uma interação lúdica entre o

1 Especialista em Desenvolvimento Sustentável no Semiárido com Ênfase em Recursos Hídricos - Instituto Federal Baiano - IF Baiano. Graduado em Serviço Social pela Universidade Norte do Paraná - UNOPAR

2 Co-orientador.

${ }^{3}$ Orientador. 
conhecimento tradicional e intervém a partir da produção de novos conhecimentos, servindo de valorização da cultura local por meio das narrativas e, ao mesmo tempo, possibilitando problematizar a questão da recuperação das áreas degradadas da Lagoa Grande, usando um aplicativo eletrônico como ferramenta educacional.

Palavras-chave: Educação Indígena, Conservação da água, Interculturalidade, Jogos Eletrônicos.

\section{INTRODUÇÃO}

A presente pesquisa foi realizada na comunidade indígena Kiriri situado no município de Banzaê ao norte da Bahia, há $326 \mathrm{~km}$ da capital do estado. Teve como foco o uso de um aplicativo Kiriri que foi desenvolvido a partir das narrativas indígenas que, associado ao uso de novas tecnologias, contribui no processo educacional, pois as novas gerações à medida que acessam tais recursos podem reportar a narrativa dos ancestrais contadas pelos mais idosos e sobre a conservação da água.

O aplicativo utilizado neste estudo foi desenvolvido pelo projeto TEC-IARA: Jogos para aprendizagem e valorização da água nos territórios indígenas da Bahia, financiado por meio do Edital ANACAPES no 18/2015, tendo seu início em 2016 e término em abril de 2017 e teve como autores professores do Instituto Federal Baiano e um colaborador externo (CARVALHO; FERREIRA; SOARES NETO, 2017). Os jogos[4] possuem um caráter multidisciplinar e envolvem conhecimentos das áreas da antropologia, agronomia, etnobotânica, hidrologia, etnopedologia, informática e pedagogia.

A fim de aferir o processo e sua efetividade, a pesquisa realizada foi desencadeada na fase final e depois de concluído o TEC-IARA. Buscou-se descrever a percepção dos professores, alunos e lideranças da comunidade indígena Kiriri; analisar o aplicativo e seu uso, bem como, saber quais as dificuldades encontradas no seu manuseio e dessa forma conseguir realizar uma reflexão sobre a percepção desses sujeitos acerca do jogo eletrônico. 


\title{
2. METODOLOGIA E DADOS DE PESQUISA
}

A metodologia foi dividida em três momentos: sendo que no primeiro abordamos a comunidade de Mirandela, pois antes de tudo, é necessário conhecer a localidade, seus sujeitos, a escola e as narrativas indígenas. O segundo momento, apresentamos o projeto TEC-IARA em sua totalidade, o jogo que foi aplicado na comunidade e o terceiro, foram apresentadas a coleta de dados, tendo sido realizadas entrevistas semiestruturadas com dez entrevistados, sendo eles duas lideranças, quatros professores, dois alunos do Ensino Fundamental I e II, um diretor escolar e um assistente administrativo. Antes das entrevistas aos sujeitos foram informados junto da pesquisa e que função eles teriam nela. Após tal conhecimento do termo, cada entrevistado assinava o Termo de Consentimento Livre Esclarecido - TCLE (anexo 1), por meio do qual solicitávamos a autorização para a divulgação dos dados coletados. As entrevistas foram gravadas no dia 01 de agosto de 2018 e os sujeitos entrevistados foram escolhidos de forma espontânea através de abordagem através de conversa.

A entrevista teve como base o que afirma Macedo (2010, n.p.):

\begin{abstract}
Que um encontro entre pessoas que dialogam numa roda de conversa, as informações adquiridas esporádicas foram intencionalmente estruturada com membros da comunidade que são elementos importantes da observação participante, seja uma entrevista aberta ou semiestruturada trata-se de um encontro real entre pesquisador e os atores sociais visando à absorção das informações mais relevantes sobre o cotidiano da comunidade e suas relações com o objeto de estudo.
\end{abstract}

Para esse levantamento de informações sobre a comunidade, registrarmos o cotidiano da comunidade indígena Kiriri em diários de bordo para a descrição dos resultados alcançados e a entrevista semiestruturada (um momento). Somando-se aos diários de bordo, utilizamos como fontes secundárias e registros fotográficos. 


\subsection{COLETA DE DADOS}

\subsubsection{DIÁRIO DE BORDO}

O diário de bordo constitui-se num instrumento por intermédio do qual o sujeito pesquisador faz um conjunto de narrativas acerca de suas ações e experiências diárias, o que the dá condições de proceder a uma espécie de processo de ruminação intelectual, haja vista, por meio dos registros de suas narrativas, poder (re) pensar as suas ações, lançando um olhar mais atento sobre que o fez e o fazer considerações sobre o que pode ser melhorado. A habilidade de reflexão tende a se tornar mais apurada com o passar do tempo, gerando no pesquisador uma mais ampla capacidade de crítica e autonomia intelectual e científica.

Nesse sentido, Porlán e Martín (1997, p. 52) compreendem que "o diário deixa de ser exclusivamente um registro do processo reflexivo, para converter-se progressivamente em organizador de uma autêntica investigação profissional".

Os instrumentos considerado na coleta de dados foram o diário de bordo informando todo o processo vivenciado através de relatos e observações. Esse processo é relevante para o pesquisador dando-Ihe a possibilidade de rever seus conceitos, ampliar seu conhecimento, fazer anotações, comentários e descrever de forma coerente a realidade observada. Ao lançar mão do diário de bordo, o sujeito pesquisador desenvolve oportunidades e habilidades intrapessoais de reflexão, o que torna o diário de bordo um instrumento constituinte e formativo do sujeito.

Ao longo de todo o processo de pesquisa e de imersão na realidade da comunidade indígena Kiriri, adotamos um diário de bordo com a narração das vivências do pesquisador em cada visita feita, levando em consideração os conhecimentos prévios adquiridos em visitas anteriores ao projeto e através de registros fotográficos. Esse diário é composto por três momentos específicos - o primeiro e o segundo realizados durante o projeto como uma pesquisa prévia e o terceiro momento após a realização do projeto, para a coleta dos dados necessários. Esses momentos serão objeto de discussão no item 7- discussão e resultados. 


\subsubsection{ENTREVISTAS}

Com relação às entrevistas, estas foram realizadas na comunidade indígena de Mirandela ao término do projeto TEC-IARA que foi realizado para crianças, jovens e adultos da Escola Indígena José Zacarias, o qual lança mão de um quiz de desenhos de agroecossistemas que abordam a recuperação e conservação da Lagoa Grande e elementos do bioma local.

Como já mencionado, a coleta de dados foi feita através de conversas e entrevista semiestruturada realizadas no dia da apresentação do aplicativo com lideranças locais e os indígenas que estavam presentes na reunião.

Os resultados obtidos se encontram na discussão e resultados dos dados e no decorrer do trabalho.

\subsection{A COMUNIDADE DE MIRANDELA}

\subsubsection{A COMUNIDADE E OS SUJEITOS}

O povo Kiriri constitui hoje um grande exemplo de luta para outros povos indígenas localizados na região Nordeste do país, no município de Banzaê- BA. Segundo a Fundação Nacional de Saúde - FUNASA (2010), o total de índios Kiriri era de 2.082 indígenas distribuídos em 12 aldeias/comunidades em 12.299 hectares nos municípios de Banzaê e Quijingue, Bahia (ANAI, 2011). Durante o desenvolvimento da pesquisa e nos encontros com a comunidade, se pode perceber e inferir que todos participavam em isonomia, tendo vez e voz para se expressar e apresentar suas possíveis proposições. Neste espaço de tempo, foi observado também que possivelmente a comunidade se sente representada pela sua liderança. Todos se sentem à vontade e respeitados pelas lideranças e pela comunidade. O grupo apresenta-se conscientes e capazes de enfrentar as dificuldades encontradas no seu dia-a-dia.

Percebe-se que a tomada de decisões é feita de maneira participativa levando em conta as consequências dos seus atos e responsabilidades, bem como seus deveres 
como líderes para com povo. Uma característica desse grupo é a existência do respeito entre todos que convivem na comunidade indígena. A terra é um elemento básico de sobrevivência dos Kiriri. O território indígena Kiriri tem sua forma octogonal (Figura 1), dividindo-se em onze núcleos, a saber: Araçá, Baixa da Cangalha, Baixa do Juá, Cajazeira, Canta Galo, Gado velhaco, Lagoa Grande, Marcação, Mirandela, Pau Ferro e Segredo. Todas essas comunidades são reconhecidas pela FUNAI.

Figura 1- Território Indígena Kiriri

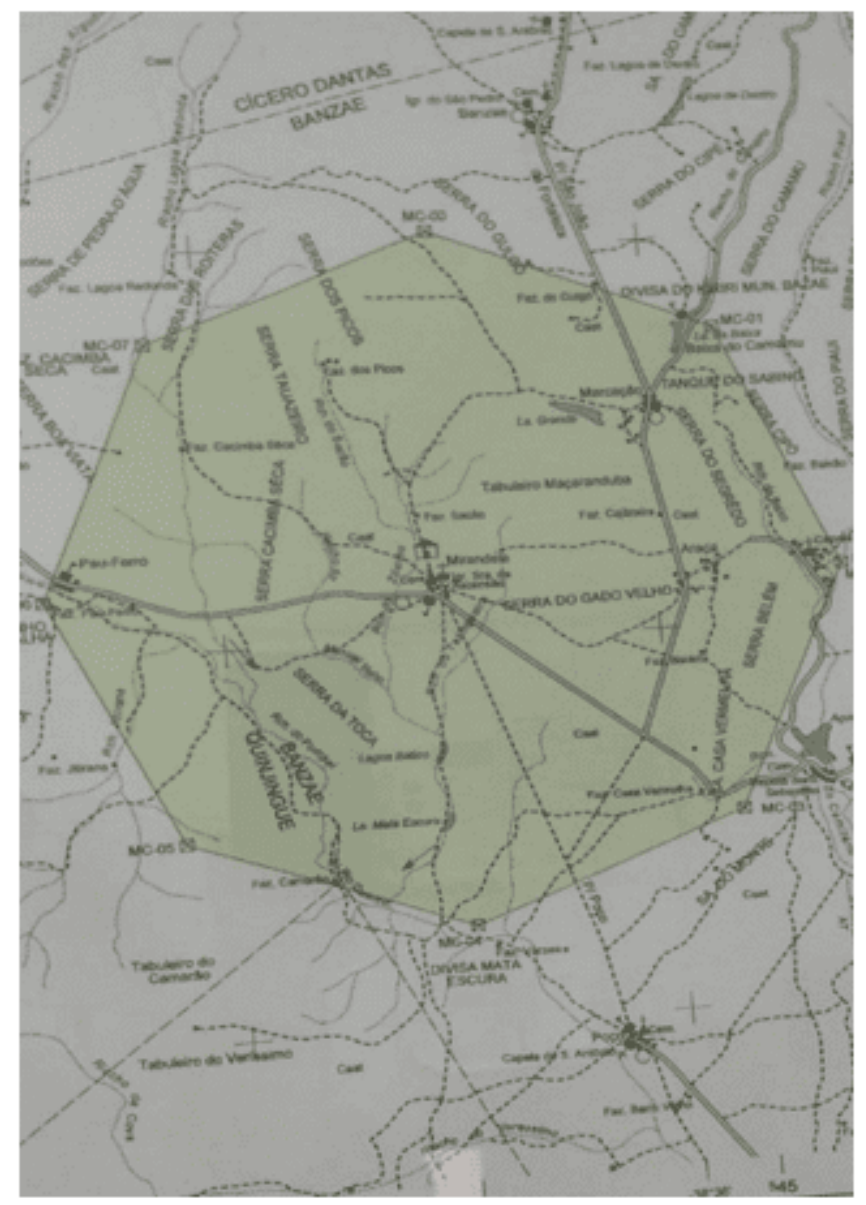

Fonte: FUNAI (2017)

A aldeia de Mirandela é composta por uma escola, uma igreja bastante antiga, cuja estrutura do teto está precária, inclusive a partir dos relatos houve um desabamento do teto há alguns anos atrás, e apesar disso, a comunidade ainda se utiliza dela de maneira limitada. Há ainda uma praça central e uma quadra de esportes. A 
infraestrutura das ruas é precária, pois não existe rede de saneamento básico, a maioria das casas é antiga, feita de adobe. Em 2016, foram construídas 198 unidades habitacionais do Programa Nacional de Habitação Rural - PNHR.

É muito forte a questão cultural indígena no que se refere às vestimentas, uma vez que adultos e crianças usam uma tanga por cima de um short, essa tanga é feita da fibra da palha do licurizeiro (Syagrus coronata), que eles denominam "pindoba". Outro acessório que é usado pelos homens é uma capanga (aió) feita de fibra de sisal, da pindoba ou caroá (Neoglasiovia variegata) que serve para colocar seus pertences quando vão a campo ou viajam. Outra questão que nos chama a atenção é assistir as crianças e adolescentes fazendo o uso do cachimbo com fumo. Para os indígenas essa é uma forma natural, um hábito cultural em momentos festivos.

A dança também está presente na comunidade através do toré entre os índios, o toré representa um símbolo de união e de etnicidade, fornecedor de elementos ideológicos de unidade e de diferenciação e, portanto, fonte de legitimação de objetivos políticos. Segundo (MARTINS, 1985):

Sobre a estrutura do toré aprendido, os Kirri introduziram novos elementos: seus "encantados" (seres sobrenaturais), acrescentados àqueles tomados de empréstimo dos Tuxá, progressivamente assumiram lugar de destaque; ao repertório melódico original, os Kiriri adicionaram seus próprios toantes e mesmo as bases coreográfica e de vestuário têm passado por inovações.

Para compreender a comunidade em seu modo de viver de se relacionar, é fundamental entender seus costumes e crenças, entender que as lideranças têm um papel de aconselhamento, mobilização e de constituir e entender origem da identidade indígena. É imprescindível considerar a força da sua cultura por meio de narrativas que são contadas pelos mais velhos da comunidade.

\subsubsection{A ESCOLA JOSÉ ZACARIAS E SEU PROJETO POLÍTICO- PEDAGÓGICO}

A escola fica situada na comunidade de Mirandela e é composta por cerca de 540 alunos distribuídos em três anexos Mirandela, Araçás e Marcação. Em Mirandela são 
340 alunos nos três turnos e 10 professores, informação acolhida junto à direção escolar. Sua estrutura física contém salas de aula amplas, cozinha, área externa coberta que serve para realizar atividades da escola, banheiros masculino e feminino, sala da direção e outra para apoio dos professores. No geral, sua estrutura tem a característica parecida de uma creche do Governo Federal e todas as entradas de portas já estão no formato adaptado para cadeirantes.

O Projeto Político-Pedagógico Escolar Indígena - PPP tem como objetivo disseminar o conhecimento sistemático da cultura geral, o conhecimento sobre a realidade e a história da comunidade indígena Kiriri, bem como o domínio de conhecimentos e temáticas relacionados à vida cidadã e à inserção e convivência em sociedade. Nesse propósito, a escola Estadual Indígena José Zacarias agrega à sua proposta curricular o estudo de temas transversais junto aos alunos do Ensino Fundamental I e II, pois, quando se educa para a cidadania, faz-se indispensável o trato reflexivo de questões sociais e que envolvem a convivência em sociedade para promoção de aprendizagem e de uma cultura de reflexão sobre o que se vive em nível local.

Segundo os Parâmetros Curriculares Nacionais de 1aa $4^{a}$ série - PCN (Brasil, 1997):

A transversalidade diz respeito à possibilidade de se estabelecer, na prática educativa, uma relação entre aprender na realidade e da realidade de conhecimentos teoricamente sistematizados (aprender sobre a realidade) e as questões da vida real (aprender na realidade e da realidade) ( p. 31).

Dado o seu caráter amplo de formação e, na escola indígena de Mirandela, os temas escolhidos são propostos pelos professores em conjunto. Do processo de escolha dessas temáticas, resultaram os seguintes temas: Terra e Preservação da Biodiversidade; Autossustentação, Direitos, Lutas e Movimentos; Ética; Pluralidade Cultural e Saúde e Educação. Tais temas encontram-se ancorados nos documentos oficiais que norteiam a política educacional.

O PPP constitui-se um instrumento de efetivação dos currículos escolares. No caso dos indígenas há traços particulares que apontam a necessidade de um processo de ensino e aprendizagem pautados em modelos específicos de educação, como a 
Educação Escolar Indígena, pretendendo-se desenvolver nos indivíduos o senso crítico, o conhecimento de sua cultura no que tange sua ancestralidade e a capacidade de criar estratégias de defesa do território em que vivem, fortalecendo cada vínculo com a natureza e, dessa forma contribuindo para o bem estar da comunidade e fortalecimento da sua identidade sociocultural (Projeto Político-pedagógico PPP da Escola Indígena José Zacarias, 2018).

Nesse sentido, a organização do currículo elaborado a partir do contexto socioeconômico da comunidade escolar irá permitir ao educador o desenvolvimento de uma prática pedagógica voltada a beneficiar os alunos, tanto em termos de formação intelectual como também em relação ao conhecimento e valorização do contexto em que esses alunos se encontram inseridos.

Identifica-se que no PPP não existem temas relacionados aos Recursos Hídricos, isso é percebido através das falas dos professores que trabalham as temáticas de forma geral em todos os momentos. Podemos mencionar em:

[...] dentro do PPP está abordando essa questão da biodiversidade na questão do meio ambiente inclusive e principalmente né por ser indígena. Porque sempre tá tem que tá falando esse questionamento na questão da preservação de um tudo, do meio que vivemos (Sic).

[...] sim, porque geralmente estão fazendo os planos semanal sempre envolve isso, eles sempre envolvem a preservação do meio ambiente e envolve a água também (Sic).

[...] temos previsão sim de trabalhar tudo que está proposto do PPP da escola, sempre trabalhamos levando a nossa realidade (Sic).

De acordo com a fala de uma professora e do diretor escolar todos os temas propostos no PPP da escola são trabalhados de acordo com a realidade da comunidade de Mirandela. Por mais que a escola tenha seu diferenciador por se tratar de uma escola indígena e resgatar os valores, a proposta apresentada em seu PPP é trabalhada de forma geral em todas as séries existentes. Isto significa resgatar a escola como espaço público, lugar de debate, do diálogo, fundado na reflexão coletiva, conforme Veiga (2004, p.14). O PPP pode ser construído por meio das discussões e reuniões que envolvem toda a 
comunidade escolar, entre equipe administrativa, financeira, pedagógica, alunos, familiares e a comunidade. No entanto, a ideia de participação, entendida como uma "modalidade de gestão que por meio da distribuição de responsabilidades, da cooperação, do diálogo, do compartilhamento de atitudes e modos de agir..." (LIBANEO, 2004, p. 103), parece contraditória, uma vez que os discursos revelam a consciência da necessidade da participação de todos no processo de construção e implementação do PPP. Mas, ao serem indagados sobre como foi construído o PPP da escola, percebe-se que essa participação ainda não é efetiva e tampouco a escola conseguiu envolver todos os sujeitos.

Outra situação relevante observada e que demonstra mais uma fragilidade, é que em nenhum momento o PPP da escola faz um diálogo com o jogo TEC-IARA, mesmo porque a proposta do jogo veio de outros espaços e sujeitos para dentro da escola. Muito embora a água seja um tema presente entre os Kiriri, seja pela perda de suas lagoas (assoreadas e secas há mais de 10 anos) seja por estarem vivendo no bioma caatinga, onde o elemento água é uma questão central.

\subsubsection{AS NARRATIVAS DO CABOCLO E COBRA GRANDE}

Na comunidade existem diversas narrativas que são transmitidas oralmente e que tem o intuito de socializar e propagar histórias contadas pelos mais velhos, essas narrativas também são apresentadas pelo aplicativo TEC-IARA. A narrativa dos Índios Tupinambá que relata a existência dos caboclos d'agua, uma figura humana de mais ou menos um metro de altura, que tem pele escorregadia e alimenta-se de peixe, os Kiriri relatam que os caboclos cortam as redes dos pescadores, vivem no fundo da lagoa. Os Indígenas relatam também que os negros d'água vivem no fundo do rio, e que aparecem à noite batendo no fundo das canoas e embarcações.

A narrativa que é contada na comunidade é da Cobra Grande. Na comunidade existia uma lagoa de onde os indígenas tiravam seu sustento, e que nessa lagoa existia uma Cobra Grande encantada que rondava por toda lagoa, cobra que protegia esse bem precioso, a lagoa. Os mais antigos relatam que essa cobra se encontrava escondida 
e só aparecia em tempo de trovoada quando a lagoa enchia. A cobra voltava a habitar e boiar sobre as águas da lagoa, denominada Lagoa Grande.

Essa narrativa, pela sua força como elemento identitário da comunidade, foi escolhida para a produção do jogo do aplicativo TEC-IARA. O projeto foi aplicado com professores e estudantes das escolas indígenas e, da sua implementação didática, ocorreu a publicação de um manual de orientações acerca do jogo para uso em celulares e computadores on line e off line, bem como a produção de um quebracabeça da reconstituição da Lagoa com o retorno de sua protetora - a Cobra Grande, que se encontra recolhida na serra da Arrasta, segundo relatos coletados.

Por meio dessas narrativas foi construído um aplicativo de celular chamado TECIARA: Jogos para Aprendizagem e Valorização da Água em Território Indígenas da Bahia. Este jogo visa atender as demandas da educação do campo e dos jovens da educação indígena na Educação Básica, em escolas de territórios tradicionais indígenas na caatinga, propagando os saberes locais sobre a água e seu uso racional. A ideia basilar é desenvolver a consciência de conservação por meio de um aplicativo com retratação da realidade desses povos indígenas e através do desenvolvimento de um conteúdo para crianças, jovens e adultos.

Trata-se de instrumentos didáticos que associam o contemporâneo com o tradicional. Assim, os jogos didáticos eletrônicos e jogos como quebra-cabeças, de encaixe, abordam temas como ciclo hidrológico associado à conservação de solos, produção em sistemas agrícolas agroecológicos e uso racional da água para a população e para os animais. Os jogos apresentados nos levam a refletir sobre o conhecimento tradicional, sobre as narrativas e o conhecimento oral desse povo. Carvalho, Ferreira e Soares Neto (2018, p. 130.) dizem que: "As narrativas da Cobra Grande, assim como as do Caboclinho-do-poço, eram recados para que a natureza seja conservada e a importância da água como um bem de todos".

As narrativas têm um valor muito importante para a comunidade tornando assim um patrimônio para o povo Kiriri. Rodrigues Júnior (2010, n.p.) afirma que: 
As narrativas se tornam um patrimônio biocultural, que é o conhecimento, inovações e práticas dos povos indígenas, que abrange dos recursos genéticos que eles desenvolvem, às paisagens que eles criam. Seus componentes operam inextricavelmente ligados na prática diária e visão de mundo dos povos indígenas, e são mantidos através das gerações, graças aos valores culturais e espirituais.

Assim, a pesquisa desenvolvida remete-se a uma abordagem dentro do comportamento e cultura dos índios Kiriri, dando margem interpretativa e inferencial ao objeto estudado. Nesse sentido, busca-se examinar os elementos in loco, tentando perceber os fenômenos e as narrativas por meio dos significados, percepções e compreensões singulares dos Kiriri, agregando-os à realidade experimentada e observada pelo pesquisador.

Sabemos que a pesquisa de cunho etnográfico tem como foco entender a cultura da comunidade e grupos sociais formados. O processo de investigação teve seu início no momento da primeira oficina de apresentação do aplicativo na comunidade, afinal, "[...] muito do que se sabe sobre relações de campo, sobre abertura e direcionamento rumo a um campo e seus membros, sabe-se através da pesquisa etnográfica" (ANGROSINO, 2009).

Os relatos aqui apresentados mostram a percepção dos professores e lideranças com relação à importância e à necessidade de se trabalhar as narrativas na escola, pautando as questões culturais, conforme depoimentos coletados.

[...] Aqui nesse espaço trabalhamos com dramatizações as narrativas, então porque muitos jovens eles nascerem já aqui, nós temos mais de 20 anos que temos no território, ele não tem conhecimento do que os mais velhos passaram dos velhos sofreu. E nisso precisa ser contado e o espaço que é mais cobrado e é um espaço de construção é a escola, por isso a luta pela educação indígena, todos os professores e estudantes é indígena. (sic).

[...] todos os temas narrativas são trabalhados na sala de aula, os professores contam na sala de aula e os maiores já fazem apresentação das narrativas, nunca deixamos de fugir essas histórias na vida da gente. (sic)

[...] sempre vejo pessoas ao redor da Lagoa em comunhão se encontrando conversando... Mas é uma prática comum final da tarde tem muitas pessoas ali jovens adultos crianças que por estarem na 
mesma atividade e acabam conversando estou indo contando história e mantendo viva a cultura. (sic)

É muito importante que se trabalhe a narrativa não só com os alunos da escola estadual José Zacarias, mas sim com toda a comunidade Kiriri resgatando assim valores culturais, pois é através deste resgate que a formação cultural é disseminada. Outra questão a ser trabalhada é sobre a forma que a narrativa é apresentada aos alunos, que a narrativa não seja apresenta apenas através de dramatização ou conto, e sim, que seja feito uma reflexão de resgate de valores com alunos e demais indígenas no intuito de fazer conhecida a narrativa.

\subsection{O PROJETO TEC-IARA}

\subsubsection{O PROJETO}

O projeto foi desenvolvido pelos professores do Instituto Federal de Educação, Ciência e Tecnologia Baiano Aurélio José Antunes de Carvalho (coordenação) e Marcio Harrison dos Santos Ferreira; e um colaborador externo Carlos de Azevedo Pinto Soares Neto. O projeto que visava atender educação do campo, especialmente, jovens da educação indígena do ensino básico em escolas de Territórios tradicionais indígenas na Caatinga e na Mata Atlântica na Bahia, expondo sobre os saberes locais sobre a água, seu uso racional a ser utilizado na educação básica indígena. Por meio de jogos didáticos eletrônicos e jogos como quebra-cabeças, encaixe, abordando temas como o ciclo hidrológico associado à conservação se solos, produção em Sistemas Agrícolas Agroecológicos e uso racional da água para as populações humanas e animais.

\subsubsection{O APLICATIVO}

O aplicativo que o projeto menciona é um programa que pode ser usado no computador concebido para acessar informações através de dados eletrônicos esse aplicativo é considerado educativo uma vez que o mesmo irá trabalhar as questões referentes ao aprendizado. Lançado em 24/05/2017 o aplicativo teve mais de 100 
downloads e tem classificação livre, podendo ser baixado através do Play Store do google. https://play.google.com/work

\subsubsection{O JOGO}

O jogo apresentado tem cinco fases, e para que se entenda o que foi observado é necessário que o leitor o conheça. Para jogar é necessário baixar o aplicativo em um aparelho de celular ou pelo computador e que tenha um bom sinal de internet. $O$ jogo tem cinco níveis, cada nível tem cinco perguntas. No primeiro nível, as perguntas são relacionadas à degradação; no segundo, se referem aos conceitos para entender o ambiente e a realidade; no terceiro, tem-se perguntas relacionadas aos conceitos $\mathrm{e}$ técnicas sobre o meio ambiente; no quarto e quinto as perguntas são relacionadas à recuperação da área degradada que é a lagoa. As imagens se encontram no final deste item.

A proposta apresentada através das perguntas no jogo traz estratégicas de uso de conservação das águas em territórios indígenas e a composição de sistemas agroflorestais, práticas mecânicas de desassoreamento e contenção de enxurradas, prevalecendo a máxima cobertura vegetal como elemento essencial na conservação das águas. Além dessa plataforma, foi confeccionado um quebra-cabeça com imagens de partes da comunidade indígena, imagens essas que se encontram no aplicativo, o qual pode ser utilizado por pessoa de qualquer idade. As imagens de encontram no (item 2.2.4).

Os jogos e brincadeiras apresentados pelo projeto proporcionam às crianças e aos adultos aprenderem de forma prazerosa. Por meio do entretenimento, o grupo interage e desenvolve habilidades ampliando os conhecimentos de forma autêntica proporcionando ao grupo uma aproximação da realidade com as narrativas de aprendizado.

Acerca dos jogos há várias abordagens. Há jogos que estimulam a capacidade de imaginação, outros que enfatizam regras. "O jogo é uma atividade estruturada, parte de um princípio de regras claras, de fácil entendimento" (KISHIMOTO, 2011, p. 15). 
Regras essas que ao brincar, o indivíduo (criança/adulto) talvez não tenha a preocupação de adquirir conhecimento, mas sim trata o jogo como diversão. Ao utilizar o jogo o conhecimento se torna algo reflexivo, o que propicia o desenvolvimento de habilidades intelectuais ao ser humano. Registro das imagens mostram as etapas do jogo.

Figura 2 - imagem do aplicativo

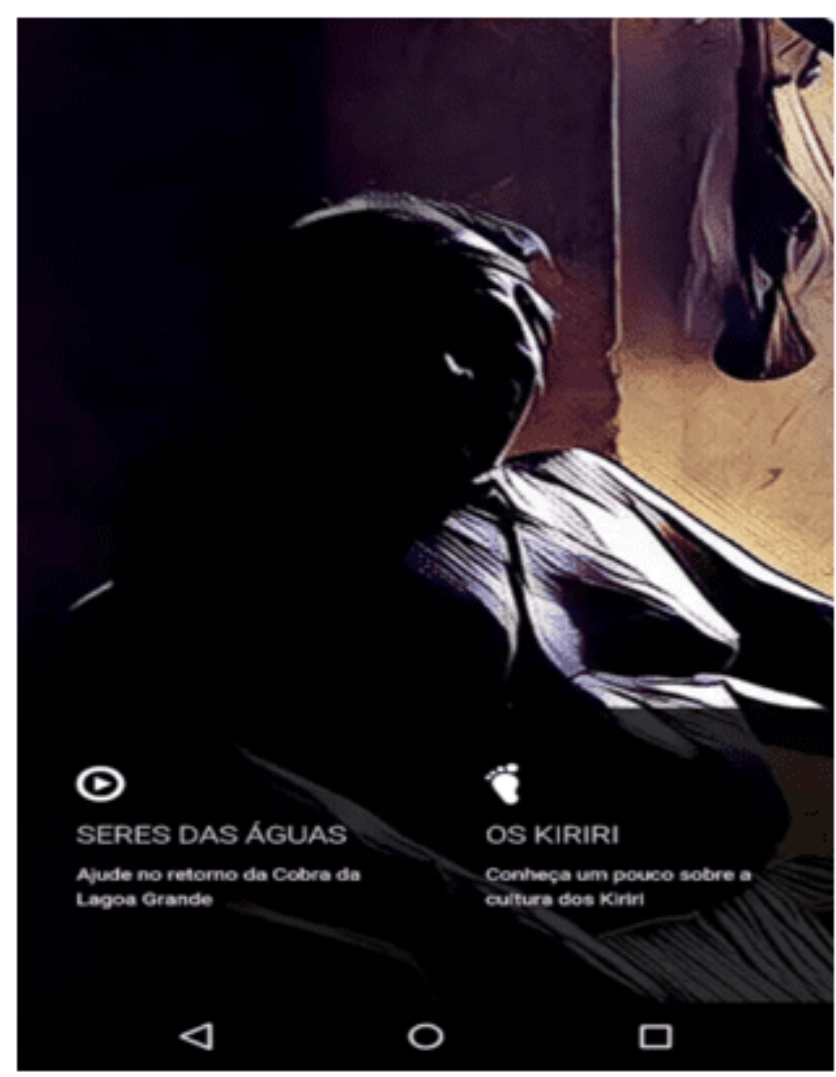

Fonte: print do celular do autor. 
Figura3 - imagem do aplicativo

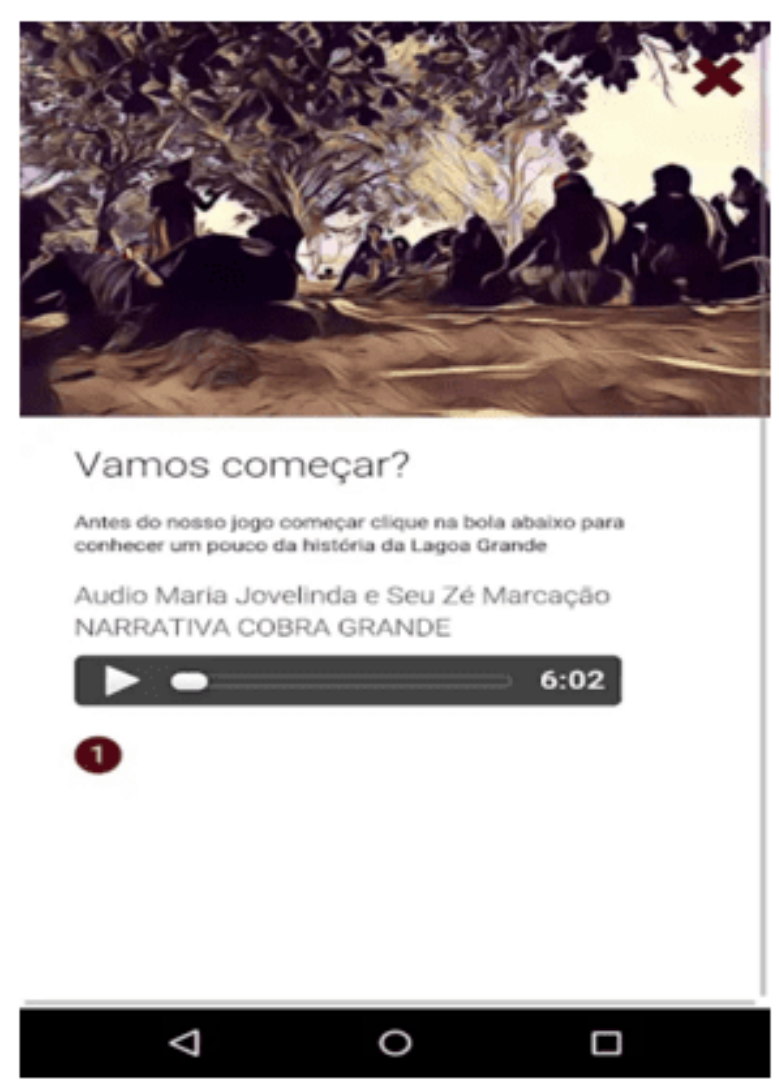

Fonte: print do celular do autor. 
Figura 4 - imagem do aplicativo

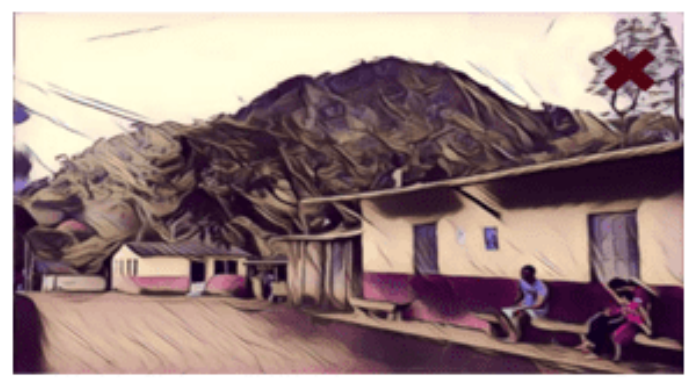

Os índios Tupinambá...

relatam a existência dos caboclos d'água, uma figura humana de mais ou menos um metro, tem pele

escorregadia. Alimenta-se de peixe, corta as redes dos pescadores.

Fonte: print do celular do autor 
Figura 5- imagem do aplicativo

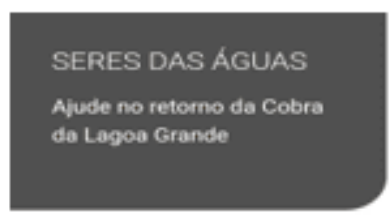

NIVEL 1 - A degradaçã̃o
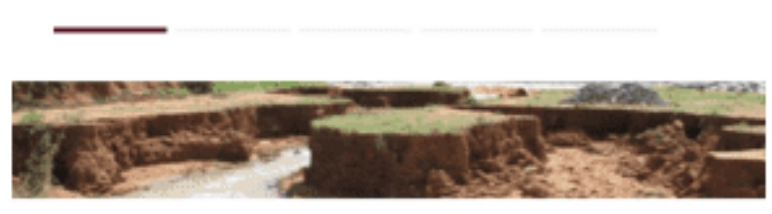

Processo de perda de solo pelas chuvas, descendo a terra desde as áreas mais altas para as mais baixas, podendo ser natural ou provocado pelo homem e favorecido pelo desmatamento.

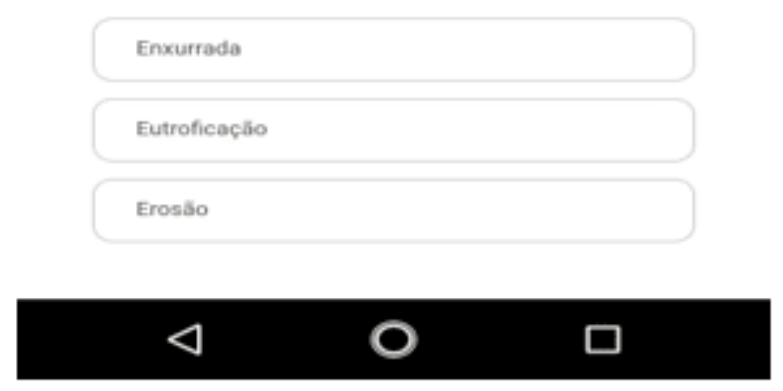

Fonte: print do celular do autor. 
Figura 6- imagem do aplicativo

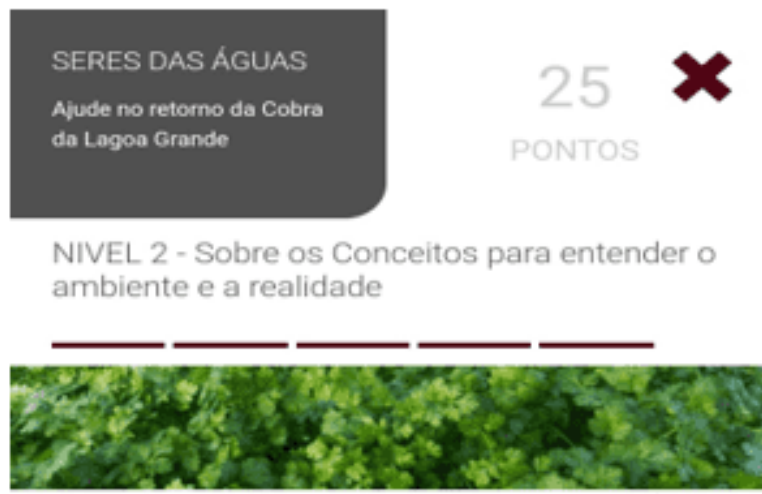

Região de transição entre dois ecossistemas diferentes

Ecologia

Ecótono

Agronomia

$\triangleleft$

$\square$

Fonte: print do celular do autor 
Figura 7- imagem do aplicativo

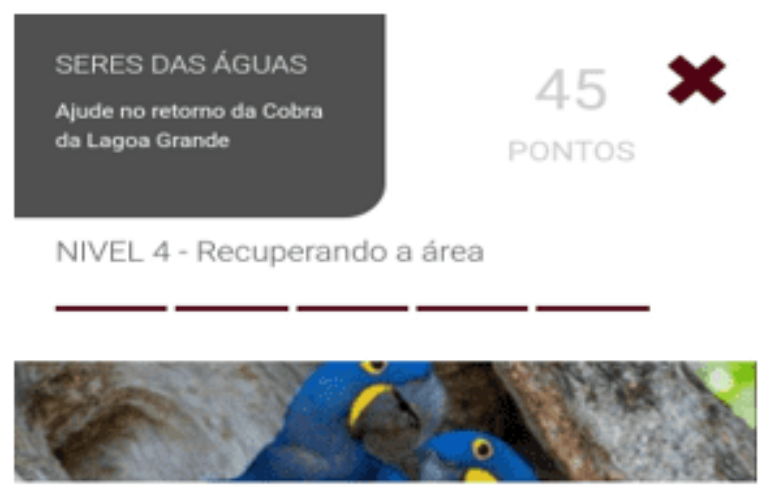

Método mecânico de retirada de materiais depositados no leito de rios e lagoas

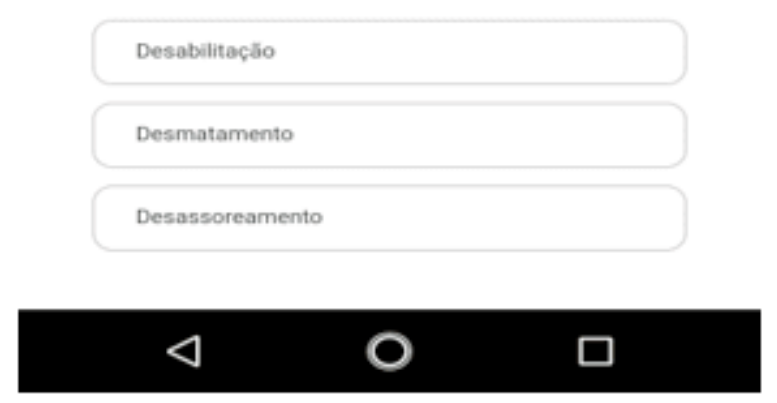

Fonte: print do celular do autor. 
Figura 8- imagem do aplicativo

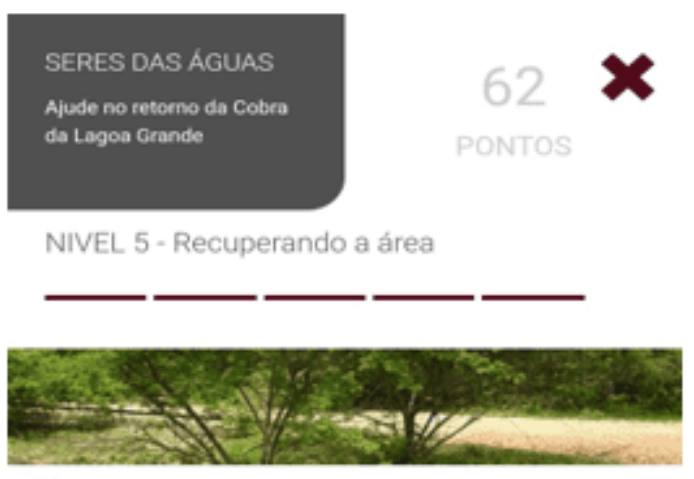

Água no sistema é associada à?

plantio apenas de roças em monocultivo

existéncia e manutençāo da cobertura vegetal

hexistència de vegetaçắ

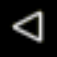

○

$\square$

Fonte: print do celular do autor 
Figura 9 - imagem do aplicativo

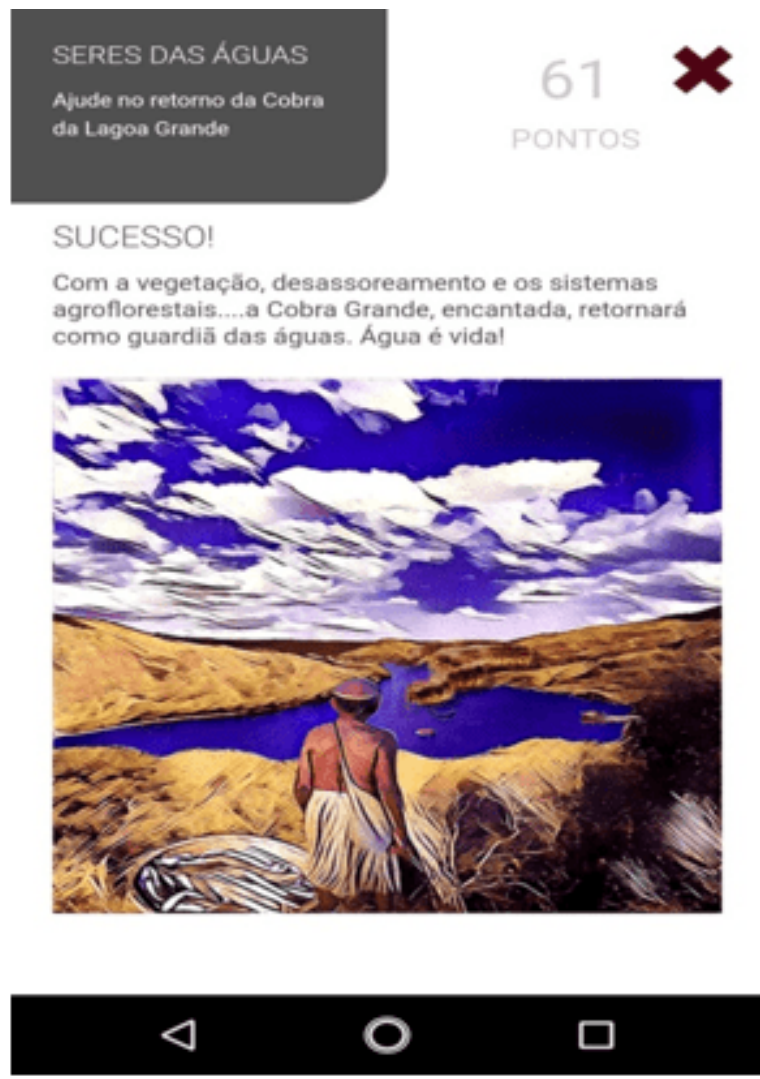

Fonte: print do celular do autor.

\subsubsection{ENTENDENDO A IDEIA DO JOGO}

O Jogo é desenvolvido com professores, estudantes e moradores da comunidade Kiriri, tendo como principio resgatar as memorias de um povo batalhador e cheios de esperanças. $\mathrm{Na}$ era digital, temos outros imperativos, novas formas de interagir, de comunicar-se, de informar-se, de educar-se.

Assim sendo, a tendência é a perplexidade das pessoas que nasceram em outro contexto, pois, enquanto essas se percebem como se encontrassem diante de uma realidade jamais imaginada, isto é, de um futuro de incertezas e desafios, os nativos digitais se sentem "em casa" e não conseguem imaginar suas vidas sem os aparatos tecnológicos, sem a virtualidade, sem uma interação global e em tempo real. Esses sujeitos cresceram imersos numa irrestrita familiaridade com celulares, com acesso à 
internet, com compartilhamento de arquivos, utilizando brinquedos e jogos eletroeletrônicos e assim por diante e, desse modo, desde muito cedo desenvolvem sua coordenação motora e sua cognição.

Estamos em um momento em que as tecnologias de informação - TI imprimem novas formas e paradigmas distintos à educação, propondo e impondo um conjunto de transformações que se fazem necessários aos estudantes contemporâneos tem um olhar diferenciado à capacidade de compreender o que é proposto. Os avanços tecnológicos estão sendo utilizados praticamente por todos os ramos do conhecimento.

Sob esse olhar, o quiz[5] tem uma gama de possibilidades de produção, aquisição e transmissão de conhecimentos tanto no mundo virtual quanto no presencial. Podemos ver a crescente disseminação da educação a distância, dos blogs instrucionais e filosóficos e de inúmeros softwares denominados educativos, estamos convivendo com um momento da educação tanto espontânea quanto interativa, por meio de programas e aplicativos que ajudam ao aluno a assimilar conhecimentos de forma mais fluida e autônoma.

A sociedade da informação e do conhecimento exigem novas formas de aprender, e requer de todos um olhar especial na busca de estratégias de ensino que fomentem no indivíduo a busca pelo conhecimento, e por apropriar-se desse conhecimento de forma positiva, garantindo o seu desenvolvimento e participação na construção e usufruto de tal conhecimento. Dessa forma se deve incentivar os alunos para ter o conhecimento, nesse caso, refere-se ao professor não como culpado, mas como mediador da informação/conhecimento entre o mestre/aluno.

Nesta perspectiva de ensino e aprendizagem, e ainda de globalização e ancestralidade é que foi pensada a produção desta plataforma de conhecimento, podendo ser utilizada de forma significativa e educativa, dentro e fora da aldeia, possibilitando estratégias e caminhos para que o professor realize suas aulas de uma forma interessante, assim como os alunos e demais usuários possam utilizá-lo. 
Para entendermos como essas estratégias e caminhos são direcionados em sala de aula foi realizada entrevista perguntando alguns pontos pertinentes ao aplicativo, que foi apresentado na comunidade no dia 18 de abril de 2017, data escolhida por conta da programação do Dia do Índio, constando na programação do evento do ano de 2017.

O jogo tem como principal objetivo resgatar a cultura local através da narrativa da cobra grande da Lagoa Grande e fazer com que a cobra volte a habitar a lagoa. Com relação ao jogo, coletamos informações acerca do que o povo Kiriri achou do quiz.

[...] Teve o material os jogos didáticos que são quebra - cabeça que no dia do índio que as crianças estavam brincando lá na casa do Cacique aquele joguinho dá também é bom porque através dos jogos didáticos também trabalha as narrativas (Sic).

[...] A escola indígena não é só formar um indígena para o mercado de trabalho, mas também tem a formação da questão da identidade do ser indígena, Se existir algum indígena que quiser fazer faculdade fora ele que ter base não só a questão da identidade, [...] aprender a se defender, aprender conhecimento. (Sic).

Existe a preocupação com relação ao ensinamento, que os professores não apenas possam ensinar o conteúdo programático referente a cada disciplina, e sim preparar os estudantes indígenas para a vida social respeitando seus valores e crenças. Dando continuidade abordaremos os relatos dos entrevistados com relação ao que acharam do aplicativo, se usaram, e dos que não usaram. Os depoimentos apresentados têm o intuito de compreender melhor o que os indígenas entrevistados pensam sobre o aplicativo.

[...] Eu conheço e conheci inclusive participo do grupo e, no entanto, já vieram abordar aqui, apresentar na escola para os demais alunos, os alunos gostaram até participaram da apresentação e teve um que conseguiu ter acesso a esse aplicativo, eu tive acesso, eu gostei ser sincera eu não fui todas as etapas, admito que fosse abordando a questão da água, sobre a questão da preservação. Pra mim eu achei o acesso fácil mais é porque eu já tenho conhecimento. (sic)

[...] Sim eu já baixei no celular uma vez, e no caso tem umas perguntas boas saber se as pessoas sabe de alguma coisa da nossa região, o objetivo disso é recuperar a lagoa que essa cobra encantada volte, e é muito bom ele. ( sic ) 
[...] No geral no caso dele, eu mesmo gostei, além de nos ensinar um pouco nos ensina a cuidar como diz é do solo, e que deve preservar mais as arvores e não acabar entupindo a lagoa e ensinar um pouquinho das nossas crenças aqui.(sic).

[...] Sobre a experiência do aplicativo que foi repassado eu usei uns tempos... Porque assim usei e é muito importante saber das histórias do passado e filho de quem da nossa comunidade tudo que acontece nas nossas aguadas , firmar.(sic)

Embora todos tenham gostado do aplicativo, o diretor escolar e os dois alunos não baixaram o aplicativo devido à memória do aparelho celular não suportar o aplicativo que tem 17,20 MB megabytes, e mesmo usando em modo off faz-se necessário ter uma boa memória de celular para o que o aplicativo possa ser usado tranquilamente. Os depoimentos apresentados informam o nível de aceitação do aplicativo. Embora tenham relatado a satisfação foi percebido que nem todos têm aparelhos de celular com memória suficiente para baixar e utilizar o aplicativo. Alguns pontos são negativos quando se referem a questão escolar, pois, a mesma não tem sala de informática com computadores e com sinal de internet suficiente para serem trabalhados esses tipos de tecnologias em sala de aula dificultando assim o ensinamento.

Com relação aos alunos que foram entrevistados foi percebido, que não tem conhecimentos nenhum acerca do aplicativo embora tenha sido apresentado para todos os funcionários e alunos, percebeu-se que nem todos tiveram a oportunidade de conhecer o jogo no dia da apresentação e após a apresentação remetendo assim que o jogo seja reapresentado futuramente na escola.

Faz-se necessário que o aplicativo também seja usado em outras comunidades indígenas, e que esses momentos sejam liderados pelas lideranças locais juntamente com professores e que sejam realizadas reflexões uma vez que o aplicativo tem o objetivo de realizar estimulo aos conceitos de preservação ligados à conservação da natureza.

\section{DISCUSSÃO E RESULTADOS}

Depois de ter realizado a pesquisa de campo com os professores, alunos e lideranças da comunidade Kiriri, especificadamente, os da Escola Indígena José Zacarias, o 
material coletado objetivou realizar uma análise das respostas obtidas e fazendo comparação com o material coletado através do diário de bordo .

Contemplemos as questões e as falas dos sujeitos entrevistados: "Saber se na semana pedagógica foram discutidas questões como a água, a caatinga e o meio ambiente". As respostas, em sua maioria, mostraram a preocupação com o aprendizado, porém somente os professores responderam.

[...] e nossa atividade do dia 13 de abril que a gente trabalha mais ou menos um mês só a questão da comunidade depois no final nos faz uma exposição, mesmo assim trabalhando o que tem no livro que ser o professor é cobrado por isso, temos que trabalhar o que tá escrito na base nacional e temos também que trabalhar a com a comunidade com os assuntos. (Sic)

[...] Sim, dentro do que está proposto em nosso PPP que tem isso bem vista, está previsto sim a gente trabalhar as atividades que estão proposta lá. Como a gente fala em preservação da natureza, temos que preservar essas coisas principais e a água é uma delas. ( Sic)

Todas as propostas apresentada no PPP da escola trabalham a questão ambiental de forma indireta, os professores realizam as atividades de acordo a realidade local. A semana pedagógica realizada na escola não foi trabalhada a questão dos recursos hídricos. Outra questão que o PPP não estava disponível ao público dificultando assim 0 acesso.

"Saber se o aplicativo foi utilizado em sala de aula, se usaram, o que acharam e, se não usaram, vamos usar agora? " as respostas, em sua maioria, foram positivas, os sujeitos mostraram o seu interesse sobre o aplicativo. Dois deles baixaram o aplicativo durante a entrevista, bem como uma professora disse ter usado o aplicativo em sala de aula. Os professores, alunos e lideranças responderam a essa questão.

[...] O aplicativo quando os professores vieram aqui apresentaram, e na construção eu participei também e assim, cheguei a baixar e fui fazendo as perguntas né na medida que vai fazendo vai avançado as perguntas, não é que seja difícil .... as questão do app precisa totalmente do conhecimento ... precisamos dos dois conhecimentos do interno e externo. (sic)

[...] Não porque o tempo que saiu eu não tinha celular. 
[...] não cheguei a ver o aplicativo. (Sic)

[...] Eu companhei essa oficina que foi apresentada na escola Zacarias, eu vi lá que é importante. Mas não sei explicar direito com navegar nesse aplicativo, tem que procurar entender mais isso aí, pode ser uma coisa mais na frente importante para nos Kiriri. (Sic).

[...] Olhe eu só ouvi falar pelo que você (Aluno da pós-graduação ) apresentou ... daí, eu fui ver na internet, no site o aplicativo de fato ainda não baixei devido a memoria do celular. Mas o que foi dito e apresentado eu achei muito interessante. Irei baixar assim (Sic).

[...] cheguei a comentar se na escola todos os professores tiveram conhecimento, e todos os estudantes e se a gente tivesse mesmo todo equipamento a gente trabalharia na sala e com os alunos. Seria interessante. (Sic).

Vale salientar que os jogos não devem ser levados à sala de aula para preencher o tempo vazio dos alunos, mas que ele venha ser um jogo divertido com objetivos de estimular e aprimorar o conhecimento de quem o joga. A escola Estadual Indígena de Mirandela não tem estrutura montada para o uso de tecnologias, tais como sala de computação que oportunize aos alunos um manuseio, familiaridade e fluidez no uso dos aparatos. A aldeia também não dispõe de um sistema telefônico adequado para dar suporte para os aparelhos tecnológicos.

Com o término do projeto TEC-IARA, acentua-se a necessidade de incentivar os professores da Escola Estadual Indígena José Zacarias e as Lideranças da comunidade a interagirem novamente com os alunos, incentivando toda a comunidade indígena a se envolver a buscar uma inserção digital, pois os jogos, as mídias e toda uma gama de aparatos tecnológicos são uma fonte de aprendizado que contribuem para a formação do sujeito para o usufruto da informação e do conhecimento como bens socioculturais.

No tocante à questão "Qual o significado da água para os povos indígenas?". A maior parte dos entrevistados diz que a questão da água é trabalhada em toda comunidade, dizendo que, dada a sua importância, o assunto está sempre em pauta. A essa questão somente professores e lideranças responderam que a água é um bem essencial para vida e uma disse com clareza sobre a questão dos mananciais superficiais locais a exemplo da Lagoa Grande e da Lagoa do Batico: 
[...] A importância da água para mim e para a comunidade é uma coisa importante como diz né mas assim, nós temos as Lagoas duas no caso nós temos em marcação, Lagoa Grande no caso né Tem Lagoa do badico aqui que é mais próximo aqui da cidade de Mirandela como são Lagoas que todas estão tão seca né (sic) .

A água é um direito universal, todos nós temos esse direito, mas junto aos direitos vêm os deveres e preservá-la é a forma mais correta para se garantir a água para o futuro. Sobre "Saber como é trabalhada a questão cultural na escola com relação às narrativas do jogo" as falas demonstraram preocupação com o aprendizado. Somente os professores responderam à questão.

[...] professor trabalhou com na comunidade, mas eu acredito que todas as inovações que estamos tendo hoje, através de um incentivo, nos podemos desenvolver esse projeto como cuidar da água, como conservar água para não desperdiçar, isso a gente pode trabalhar.(sic).

[...] Então tudo que nós planejamentos nós fazemos na escola, é toda essas atividades sempre envolvendo a questão da comunidade porque mesmo trabalhando com todos os outros conteúdo né que seja da base Nacional mas nós sempre puxando para nossa realidade, (sic) .

[...] Então como eu já coloquei todos os conteúdos da base nacional para trabalhar de acordo com a realidade indígena. (sic).

[...] Posso afirmar que é uma comunidade bem tranquila e tradicional. Tem muitas belezas e mata preservada. (sic).

Pode-se destacar a necessidade de resgatar as práticas das narrativas, contadas e repassadas intergerações. A partir do momento que essa prática cultural é enfraquecida e desestimulada, poderá cair no esquecimento, dando lugar a novas práticas que talvez não expressem ou remetam as características da comunidade. Através deste estudo podemos inferir que as narrativas fortalecem a identidade desta população indígena, e quando trabalhadas no ambiente escolar fortalece a integração e interação entre aprendizagem, escola e comunidade.

Diante do exposto faz necessário resgatar a narrativa, que é contada pelos mais velhos da comunidade, não podendo relegar as narrativas ao desconhecimento, que 
fortalece constantemente todos os indígenas sendo assim, fazer com que venha ocorrer diálogo entre o conhecimento escolar com a comunidade.

\section{CONSIDERAÇÕES FINAIS}

O aplicativo serviu de estímulo para aquisição de novos conhecimentos que são representados através da construção ativa da capacidade intelectual para operar símbolos, imagens, ideias e representações, positivando a cultura local de forma geral, os professores indígenas da Escola Estadual Indígena José Zacarias têm o conhecimento do aplicativo e da importância que o mesmo pode trazer para toda a comunidade.

Os professores e lideranças afirmam ser necessária uma iniciativa de retomada da atividade na comunidade, uma vez que, com o passar do tempo, essas atividades identitárias foram um tanto quanto esquecidas. Entretanto, cabem aos profissionais da escola provocar esse momento com alunos e demais moradores. A mobilização da comunidade incitada pela ação da escola e das lideranças, especialmente, a partir do projeto TEC-IARA demonstra avanços e limitações a serem superadas.

Alguns avanços podem ser observados com relação aos impactos do projeto TECIARA, no que diz respeito à educação para a vida cidadã, podemos vislumbrar o pontapé inicial de trabalho de formação que se coloca para além da escolarização formal e em prol da construção de um conhecimento ambiental contextualizado, com ênfase na disseminação de práticas de preservação e manejo sustentável da caatinga e dos seus recursos hídricos e, ainda, em função de uma consciência cultural que integra o conhecimento das narrativas de todos os indígenas da comunidade com os conhecimentos sistemáticos veiculados via currículo escolar.

Ressaltamos a importância de que esse aplicativo seja trabalhado em outras comunidades Kiriris, aliada a urgência de melhoria da estrutura tecnológica das comunidades, no sentido de serem contempladas com estruturas e espaços adequados, dispondo, portanto, de salas de informática em pleno funcionamento e 
que tenham um aparelho de celular com memória suficiente para que o aplicativo mesmo sendo utilizado no modo off seja baixado e utilizado.

As lagoas que existiam na comunidade secaram e para reverter tal situação são necessários investimentos públicos a fim de investir na reversão do processo de assoreamento das lagoas dos territórios indígenas, bem como desencadear processos de uso que conservem o solo e a água. Ademais, a presente pesquisa deu conta de trabalhar com o grupo Kiriri liderado por Cacique Lázaro. A Escola tem papel preponderante na comunidade indígena de Mirandela, pois pode ser considerada um local neutro, onde todos tem acesso, é considerado como um local de saber e uma conquista da comunidade local.

\section{REFERÊNCIAS}

ANGROSINO, Michael. Etnografia e observação participante. Tradução: José Fonseca. Porto Alegre: Artmed, 2009.

BRASIL. Ministério da Educação e do Desporto. Secretaria de Educação Fundamental. Parâmetros Curriculares Nacionais: apresentação dos temas transversais - ética. Brasília: MEC/SEF, 1997.

CARVALHO, A J A; FERREIRA, M H S e SOARES NETO, C A P. "Quando pensa que não...": contos, crônicas e causos em etnoecologia/ organizadores, Francisco José Bezerra Souto ...[et al.]. - v.3. Belém: UFPA, 2018212P.;21cm.

TEC-IARA: jogos para aprendizagem e valorização da água em territórios indígenas da Bahia. Disponível em: $<$ https://capacitacao.ana.gov.br/conhecerh/handle/ana/287>. acesso em 20/08/2018.

PPP: Projeto Politico-pedagógico. Escola Estadual Indígena José Zacarias. Disponível em acervo de documentação da Escola. > acesso em 01/08/2018 DANTAS, Beatriz G; SAMPAIO José Augusto L, CARVALHO Maria Rosário G de. Os povos indígenas no Nordeste brasileiro: um esboço histórico. In: CUNHA, Manuela 
Carneiro da. História dos índios no Brasil. São Paulo: Companhia das Letras Secretaria Municipal de Cultura - FAPESP, 1992.

FARIA, Wilson de. Aprendizagem e planejamento de ensino. São Paulo, Ática, 1989. Disponível em: <http://www.robertexto.com/archivo3/a_teoria_ausubel.htm>. Acesso em: 15/08/2018.

FERNANDES, Rosa Maria Castilhos. Educação permanente e políticas sociais. Campinas: Papel Social, 2016.

KISHIMOTO, Tizuko Morchida. Jogo, brinquedo, brincadeira, e a educação. 14 ed. São Paulo: Cortez, 2011.

MACEDO, Roberto Sidnei. A etnopesquisa implicada: pertencimento, criação de saberes e afirmação. Brasília: Liber livros, 2012.

MACEDO, Roberto Sidnei. Etnopesquisa critica, etnopesquisa-formação. Brasília: Liber livros, 2ª edição, 2010.

MARTINS, Marco Aurélio. O toré na Lagoa Grande. Salvador : s.ed., 1982. (paper).

LIBÂNEO, José Carlos. Organização e gestão da escola: teoria e prática. 5 ed. Goiânia: Editora Alternativa, 2004, 319p.

PACHECO, Tânia. 2007. "Inequality, environmental injustice, and racism in Brazil: Beyond the Question of Colour". In: Development in Practice. Aug. 2008, Vol.18(6). Versão em português disponível em: $<$ http://www.justicaambiental.org.br/_justicaambiental/pagina.php?id=1869>. Acesso em 04/05/2018.

PAPERT, Seymour. A máquina das crianças: Repensando a escola na era da informática; trad. Sandra costa. Porto Alegre: Artes Médicas, 1994.

PIAGET, Jean; GRÉCO, Pierre. Aprendizagem e conhecimento. Tradução: Equipe da livraria Freitas Bastos. Rio de Janeiro: Freitas Bastos, 1974. 
PORLÁN, Rafael; MARTíN, José. El diario del profesor: um recurso para investigación en el aula. Sevilla: Díada, 1997.

SANTOS, Milton. O chão contra o cifrão. Folha de São Paulo, São Paulo, 28 fev.1999. Caderno Mais, p.5. SRH (org.). Justiça pelas Águas: enfrentamento ao Racismo Ambiental. Salvador: Superintendência de Recursos Hídricos, 2008.

TEC-IARA- Jogos para aprendizagem da água territórios indígenas da Bahia, Disponível em: <www.kiriri.com.br>. Acesso em: 20/07/2018.

VEIGA, Ilma Passos A. Educação Básica e Educação Superior: Projeto político pedágógico. Campinas, SP: Papirus, 2004.

\section{ANEXOS}

\section{ANEXO 1}

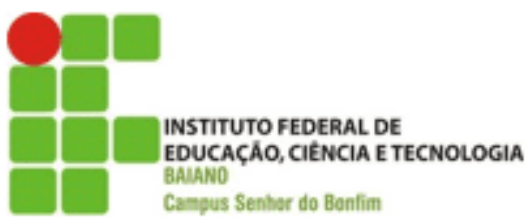

INSTITUTO FEDERAL DE EDUCAÇÃO, CIÊNCIA E TECNOLOGIA BAIANO CAMPUS BAIANO

ESPECIALIZAÇÃO EM DESENVOLVIMENTO SUSTENTÁVEL NO SEMIÁRIDO COM ÊNFASE EM RECURSOS HÍDRICOS

TERMO DE CONSENTIMENTO LIVRE E ESCLARECIDO - TCLE

BASEADO NAS DIRETRIZES CONTIDAS NA RESOLUÇÃO CNS №466/2012.

1. Prezado (a) Senhor (a) Esta pesquisa é sobre jogos para valorização da cultura indígena com ênfase nas narrativas sobre recursos hídricos dos kiriris, BanzaêBa e está sendo desenvolvido por Janderson Igo Ferreira Guirra dos Santos, 
do Curso de Especialização em desenvolvimento sustentável no semiárido com ênfase em recursos hídricos do Instituto Federal de Educação, Ciência e Tecnologia Baiano, sob a orientação dos Professores Aurélio José Antunes de Carvalho e Márcio Harrison dos Santos. Os objetivos do estudo são coletar matérias através de depoimentos, documentos escritos como tema relacionado aos recursos hídricos (água). A finalidade deste trabalho é contribuir para a conclusão do artigo da Especialização.

Solicitamos a sua colaboração para realizar uma entrevista semiestruturada, como também sua autorização para apresentar os resultados deste estudo em eventos da área da Educação e publicar em revista científica nacional e/ou internacional. Por ocasião da publicação dos resultados, seu nome será mantido em sigilo absoluto.

Esclarecemos que sua participação (ou a participação do menor ou outro participante pelo qual ele é responsável) no estudo é voluntária e, portanto, o(a) senhor(a) não é obrigado(a) a fornecer as informações e/ou colaborar com as atividades solicitadas pelo Pesquisador(a). Caso decida não participar do estudo, ou resolver a qualquer momento desistir do mesmo, não sofrerá nenhum dano.

O pesquisador estará à sua disposição para qualquer esclarecimento que considere necessário em qualquer etapa da pesquisa.

Assinatura do pesquisador responsável

Considerando que fui informado(a) dos objetivos e da relevância do estudo proposto, de como será minha participação, dos procedimentos e riscos decorrentes deste estudo, declaro o meu consentimento em participar da pesquisa, como também concordo que os dados obtidos na investigação sejam utilizados para fins científicos (divulgação em eventos e publicações).

Estou ciente que receberei uma via desse documento. Banzaê-Ba , 01 de Agosto de 2018 
Assinatura do participante ou responsável legal Contato com o Pesquisador (a) Responsável ou Impressão dactiloscópica

Caso necessite de maiores informações sobre o presente estudo, favor contatar o (a) pesquisador Janderson Igo F. Guirra através do telefone: (74) 99191-5660 ou do email janderson_igo@hotmail.com

\section{ANEXO 2}

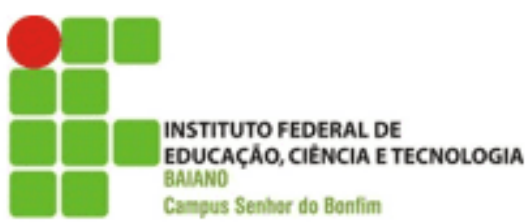

INSTITUTO FEDERAL DE EDUCAÇÃO, CIÊNCIA E TECNOLOGIA BAIANO

CAMPUS BAIANO

ESPECIALIZAÇÃO EM DESENVOLVIMENTO SUSTENTÁVEL NO SEMIÁRIDO COM ÊNFASE EM RECURSOS HÍDRICOS

\section{ROTEIRO}

Projeto Político-Pedagógico - PPP DA COMUNIDADE KIRIRI

1. Saber se o PPP da escola trata sobre a água e seu uso na comunidade;

2. A tônica da semana pedagógica qual foi? e se há presente a questão da caatinga, da água, da agricultura, do meio ambiente, território indígena ?

CARACTERÍSTICAS DO JOGO 
1. Nas conversas em sala de aula com o professor e alunos do ensino médio, saber se eles conhecem o aplicativo, se usaram, o que acharam e se não usarem, vamos usar agora ? (escrever o antes e o depois);

2. Verificar se a aplicativo esta sendo ou já foi usado em algum momento, quais partes do aplicativo mais interessaram os alunos;

3. Apresentar o aplicativo a todos os alunos(as) caso não tenha conhecimento.

\section{COLETA DE DADOS}

1. Coletar depoimentos de lideranças, alunos e professores sobre os pontos mencionados a seguir: Saber da importância da água, quais habilidades desenvolvidas na comunidade através do aplicativo.

\section{APÊNDICE REFERÊNCIA NOTA DE RODAPÉ}

4. O aplicativo e as narrativas estão disponíveis em: http://www.kiriri.com.br e https://play.google.com/store/apps/details?id=br.edu.ifbaiano.kiriri.kiriri

5. Quiz é o nome dado a um jogo ou desporto mental no qual os jogadores tentam responder corretamente a questões que Ihes são colocadas. Em alguns contextos, a palavra também é utilizada como sinónimo de teste informal para a avaliação de aquisição de conhecimentos ou capacidades em ambientes de aprendizagem.

Enviado: Janeiro, 2020.

Aprovado: Dezembro, 2021. 